\title{
The HA2 haemagglutinin domain of the lysine-specific gingipain (Kgp) of Porphyromonas gingivalis promotes $\mu$-oxo bishaem formation from monomeric iron(III) protoporphyrin IX
}

Correspondence
J.W. Smalley
josmall@liv.ac.uk

Received 11 January 2006

Revised 13 February 2006

Accepted 21 February 2006

\author{
J. W. Smalley, ${ }^{1}$ A. J. Birss, ${ }^{1}$ B. Szmigielski ${ }^{2}$ and J. Potempa ${ }^{2,3}$
}

\author{
${ }^{1}$ The University of Liverpool, Oral Microbiology Group, Department of Clinical Dental Sciences, \\ The Edwards Building, Daulby Street, Liverpool L69 3GN, UK \\ ${ }^{2}$ Department of Microbiology, Faculty of Biotechnology, Jagiellonian University, ul. Gronostajowa \\ 7, 30-387 Krakow, Poland \\ ${ }^{3}$ Department of Biochemistry and Molecular Biology, Life Science Building, University of \\ Georgia, Athens, GA 30602, USA
}

\begin{abstract}
The lysine- and arginine-specific gingipains (Kgp, and RgpA and RgpB) are the major proteinases produced by the black-pigmented periodontopathogen Porphyromonas gingivalis. They play a role in degrading host proteins, including haemoglobin, from which is formed the $\mu$-oxo bishaem complex of iron(III) protoporphyrin IX, [Fe(III)PPIX $]_{2} \mathrm{O}$, the major haem component of the black pigment. Kgp and RgpA bind haem and haemoglobin via the haemagglutinin-adhesin 2 (HA2) domain, but the role of this domain in the formation of $\mu$-oxo bishaem-containing pigment is not known. UV-visible spectroscopy was used to examine the interaction of iron(III) protoporphyrin IX monomers [Fe(III)PPIX.OH] with recombinant $\mathrm{HA} 2$ and purified $\mathrm{HRgpA}$, Kgp and RgpB gingipains. The HA2 domain reacted with Fe(III)PPIX.OH to form $\mu$-oxo bishaem, the presence of which was confirmed by Fourier transform infrared spectroscopy. Both HRgpA and Kgp, but not RgpB, also mediated $\mu$-oxo bishaem formation and aggregation. It is concluded that the Arg- and Lys-gingipains with $\mathrm{HA} 2$ haemagglutinin domains may play a crucial role in haem-pigment formation by converting $\mathrm{Fe}(\mathrm{III}) \mathrm{PPIX} . \mathrm{OH}$ monomers into $[\mathrm{Fe}(\mathrm{III}) \mathrm{PPIX}]_{2} \mathrm{O}$ and promoting their aggregation.
\end{abstract}

\section{INTRODUCTION}

Porphyromonas gingivalis, a Gram-negative anaerobe, is strongly implicated in the pathogenesis of adult periodontitis (Holt et al., 1988; Machtei et al., 1997). One of its phenotypic characteristics is the production of a black haemcontaining pigment composed of iron(III) protoporphyrin IX in the form of the $\mu$-oxo bishaem complex [Fe(III)PPIX $]_{2} \mathrm{O}$ (Smalley et al., 1998, 2002, 2004), also referred to as $\mu$-oxo dimer. It is composed of two iron(III) protoporphyrin IX molecules covalently joined through an oxygen atom interbridge, and it is this component which imparts the green-black coloration to the pigment. The $\mu$-oxo bishaem complex acts as a defensive molecule, since its formation from $\mathrm{Fe}(\mathrm{II})$ protoporphyrin IX monomers (derived from haemoglobin) ties up dioxygen and toxic oxygen intermediates (Smalley et al., 1998, 2002, 2004). Cell-surface $\mu$-oxo bishaem acts as a barrier against ingress of oxygen and reactive oxygen species and breaks down hydrogen

Abbreviations: ATR FT-IR spectroscopy, attenuated total reflectance Fourier transform infrared spectroscopy; HA domain, haemagglutininadhesin domain. peroxide through inherent catalase activity (Smalley et al., 2000).

Gingipains specific for Arg-Xaa (RgpA and RgpB) and Lys$\mathrm{Xaa}(\mathrm{Kgp})$ peptide bonds are the major proteases produced by $P$. gingivalis (Potempa et al., 1995). While Kgp is the product of a single gene $(k g p)$, Rgps are encoded by two related but individual genes $(r g p A$ and $r g p B)$. In contrast to the single-chain enzyme RgpB, mature Kgp and RgpA (HRgpA) proteins are multidomain complexes generated by proteolytic processing of the nascent translated polypeptide chains. They are composed of divergent protease domains associated with virtually identical haemagglutinin-adhesin (HA) domains. In addition to playing an important role in pathogenicity, either by degrading or inactivating proteins essential for host immunity and connective tissue integrity (see Potempa et al., 2000), gingipains are implicated in haem acquisition by proteolytic degradation of haemoglobin (Sroka et al., 2001; Smalley et al., 2004). However, it is not known whether these proteases play any other role in converting proteolytically freed haems into the $\mu$-oxo bishaem complex. The HA2 domain of Kgp and HRgpA is a receptor for both haem and haemoglobin (Nakayama et al., 
1998; DeCarlo et al., 1999; Paramaesvaran et al., 2003), whilst RgpB, lacking this domain, shows little or no binding to either haem or haemoglobin (Olczak et al., 2001). Mutants with $k g p$ truncated with respect to the HA2 domain are attenuated in haemoglobin and haem binding (Sztukowska et al., 2004). In view of these facts, we have raised the question whether the HA2 domain of Kgp and HRgpA plays an additional role in pigmentation by binding and converting haems into $\mu$-oxo bishaem, and have thus examined the interactions of HA2, and Arg- and Lys-gingipains, with monomeric iron(III) protoporphyrin IX. We report here that HA2, and HRgpA and Kgp, but not RgpB, mediate the formation and aggregation of the $\mu$-oxo bishaem complex.

\section{METHODS}

Purification of recombinant HA2. Forward and reverse primers (CGGGATCCGCAGACTTCACGGAAACGTTCG and CGGAATTCCCTTAATTTATTCCGTTAGGCGTTTCTTC) bearing restriction sites for BamHI and EcoRI were used to amplify the HA2 domain from the kgp gene. The digested PCR product was ligated into the pGEX$4 \mathrm{~T}-2$ vector (Amersham Biosciences).

The expression construct of the HA2 domain from the kgp gene in the pGEX-4t-2 vector was sequenced completely to ensure that no mutations were introduced during the cloning procedure, and was found to be $100 \%$ identical to the coding sequence. The construct was transformed into Escherichia coli BL21 and expression of the recombinant protein induced with $1 \mathrm{mM}$ IPTG when the culture reached an $\mathrm{OD}_{600}$ of $0 \cdot 5$. After $3 \mathrm{~h}$, E. coli cells were collected, suspended in PBS, and disrupted by sonication. Insoluble material was harvested by centrifugation, resuspended in $20 \mathrm{mM}$ Tris/ $\mathrm{HCl}, \mathrm{pH} 8 \cdot 0,2 \mathrm{M}$ urea, $0.5 \mathrm{M} \mathrm{NaCl}, 2 \%$ Triton $\mathrm{X}-100$, stirred for $1 \mathrm{~h}$ and subjected to centrifugation (18000 $\mathrm{g}$ for $30 \mathrm{~min}$ ). The pellet of inclusion bodies was dissolved in $50 \mathrm{mM}$ Tris/ $\mathrm{HCl}, \mathrm{pH} 8 \cdot 0,8 \mathrm{M}$ urea, $3 \mathrm{mM}$ DTT, and the solution cleared by centrifugation. To refold the protein, the supernatant was rapidly diluted in PBS then loaded on glutathioneSepharose 4 FF (Amersham Biosciences). The column was washed with PBS until the $A_{280}$ baseline was reached, and the GST-tagged HA2 domain retained on the matrix was subjected to overnight digestion with 200 units of thrombin. The released HA2 domain was eluted with $50 \mathrm{mM}$ Tris/ $\mathrm{HCl}, \mathrm{pH} 8 \cdot 5$, and purified from thrombin using a FPLC Mono Q column, and the final product was dialysed against $50 \mathrm{mM}$ Tris/HCl, $\mathrm{pH} 8 \cdot 0$.

Gingipain purification. Soluble HRgpA, RgpB and Kgp proteins were purified from the culture medium of $P$. gingivalis HG66 as described previously (Chen et al., 1992; Pike et al., 1994; Potempa et al., 1998). Briefly, HRgpA and Kgp were purified using gel-filtration and arginine-Sepharose chromatography, while RgpB was separated using a combination of gel-filtration and anion-exchange chromatography on a Mono Q FPLC column (Potempa et al., 1998). The protein content and concentration of active proteases in each batch were measured using the bicinchoninic acid (BCA) method with bovine albumin as the standard, and by active-site titration employing D-Phe-Phe-Arg-chloromethane, as described previously (Potempa et al., 1997), respectively. The purity of enzymes in each batch was checked using SDS-PAGE. RgpB migrated as a single $48 \mathrm{kDa}$ band, whilst both HRgpA and Kgp resolved into four major and one minor band on SDS-PAGE (Pike et al., 1994), the identities of which were confirmed by $\mathrm{N}$-terminal sequence analysis.

Spectroscopic methods. UV-visible spectroscopy has been widely used to study both the kinetics of dimerization (Inada \& Shibata, 1962 ) and the aggregation of iron protoporphyrin IX (Brown et al.,
1970, 1976, 1980; Silver \& Lukas, 1983; Miller et al., 1987). In aqueous solution, iron(III) protoporphyrin IX exists as a binary system comprising the monomeric and dimeric species in dynamic equilibrium, dependent upon the $\mathrm{pH}$ and the total ferrihaem concentration (Brown et al., 1976, 1980; Silver \& Lukas, 1983). At acid pH, the dominant species is the monomer, which displays a Soret band $\lambda_{\text {max }}$ at $365 \mathrm{~nm}$ and a $\beta$ band at $\sim 630 \mathrm{~nm}$, whilst at alkaline $\mathrm{pH}$ the dominant form is the $\mu$-oxo dimer, with Soret $\lambda_{\max }$ at $385 \mathrm{~nm}$ and a $608 \mathrm{~nm} \beta$ band (Silver \& Lukas, 1983; Miller et al., 1987). Iron(III) protoporphyrin IX solutions were prepared from bovine haemin (Sigma; product no. H-2250) in $0.14 \mathrm{M} \mathrm{NaCl}$, buffered at $\mathrm{pH} 6.5$ with $0 \cdot 2 \mathrm{M} \mathrm{Na}_{2} \mathrm{HPO}_{4} / \mathrm{NaH}_{2} \mathrm{PO}_{4}$, or at $\mathrm{pH} 8 \cdot 5$ with $0 \cdot 1 \mathrm{M}$ Tris/HCl, as previously described (Smalley et al., 2003), to give the monomeric and dimeric ferrihaem species, respectively (Silver \& Lukas, 1983). For calculation of the relative proportions of the haem species (see below), these solutions were taken to represent $100 \%$ monomer or $\mu$-oxo dimer. The $A_{365}$ and $A_{385}$ values for $20 \mu \mathrm{M}$ solutions of the above were used to calculate the millimolar extinction coefficients, from which the concentrations of monomer ([mon]) and dimer ([dim]) were determined according to the following equations, where $\varepsilon_{\text {mon }}$ and $\varepsilon_{\text {dim }}$ are the millimolar extinction coefficients of monomer and dimer species at these wavelengths, respectively:

$A_{365}=\varepsilon_{\mathrm{mon} 365}[\mathrm{mon}]+\varepsilon_{\operatorname{dim} 365}[\operatorname{dim}]$

$A_{385}=\varepsilon_{\mathrm{mon} 385}[\mathrm{mon}]+\varepsilon_{\mathrm{dim} 385 \mathrm{~nm}}[\mathrm{dim}]$

The values of $\varepsilon_{\operatorname{mon} 365}$ and $\varepsilon_{\operatorname{mon} 385}$ were determined as 43.9 and $41 \cdot 5$, and those for $\varepsilon_{\operatorname{dim} 365}$ and $\varepsilon_{\operatorname{dim} 385}$ as $87 \cdot 8$ and $92 \cdot 8$, respectively. Spectra were recorded in an LKB-Biochrom Ultraspec 2000 spectrophotometer, as previously described (Smalley et al., 2002), using plastic or quartz semi-micro optical cuvettes with a $1 \mathrm{~cm}$ pathlength. The relative proportions of the monomeric and dimeric species were expressed on a haem monomer basis.

Attenuated total reflectance Fourier transform infrared (ATR FT-IR) measurements were performed on liquid samples on a Thermo Nicolet instrument using a Smart Omni-Sampler. Aliquots $(80 \mu \mathrm{l})$ were placed on the sampler and 128 spectra were collected at a resolution of $4 \mathrm{~cm}^{-1}$. Haem spectra were obtained by subtraction of the background spectrum of the buffer.

Gingipain-haem interactions. HA2 and purified gingipains $(0 \cdot 2$ or $2 \mu \mathrm{M}$ ) were incubated at $37^{\circ} \mathrm{C}$ with a fixed excess concentration of iron(III) protoporphyrin IX $(20 \mu \mathrm{M})$ in $0 \cdot 14 \mathrm{M} \mathrm{NaCl}, \mathrm{pH} 6 \cdot 5$, and the spectra recorded periodically. In some experiments, HA2 $(4 \mu \mathrm{M})$ was incubated with $400 \mu \mathrm{M}$ iron(III) protoporphyrin IX in $250 \mathrm{mM}$ Tris/ $\mathrm{HCl}, \mathrm{pH}$ 7. The $\mathrm{Q}$ band region of the visible spectrum was monitored periodically, and the samples subjected to FT-IR.

\section{RESULTS}

During short-term incubation of recombinant HA2 with iron(III) protoporphyrin IX monomers there was a progressive drop in $A_{365}$, accompanied by a broadening of the Soret band and a reduction in the ratio of $A_{365}$ to $A_{385}$ (Fig. 1). These changes in the spectra are indicative of ferrihaem dimerization and aggregation (Inada \& Shibata, 1962; Brown et al., 1970, 1976, 1980). In the control haem there were slight reductions with time in both the Soret band intensity and the $A_{365}$ to $A_{385}$ ratio, indicative of a small amount of $\mu$-oxo dimer formation (data not shown). The difference spectrum made by subtraction of the haem control from the HA2 test spectrum taken after $1 \mathrm{~h}$ incubation revealed a haem $\beta$ band at $608 \mathrm{~nm}$ (Fig. 1; inset). 


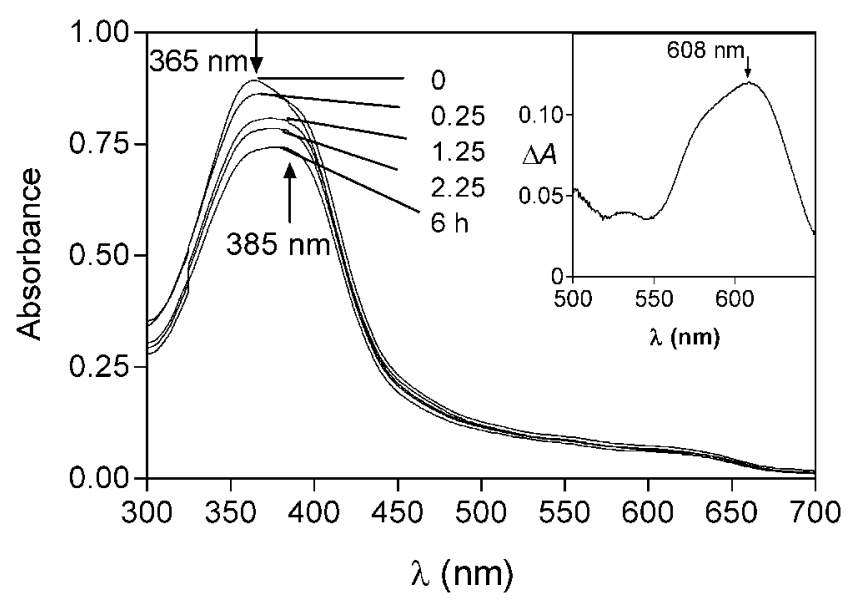

Fig. 1. UV-visible spectra of iron(III) protoporphyrin IX incubated with recombinant $\mathrm{HA} 2$ over a $6 \mathrm{~h}$ period. The molarities of the iron porphyrin and HA2 were 20 and $2 \mu \mathrm{M}$, respectively. Incubation was carried out at $37^{\circ} \mathrm{C}$ in $0.14 \mathrm{M} \mathrm{NaCl}, 0.2 \mathrm{M}$ phosphate, $\mathrm{pH}$ 6.5. Inset: difference spectrum between HA2haem and haem control after $1 \mathrm{~h}$ incubation, showing the $\beta$ band at $608 \mathrm{~nm}$ attributable to the presence of the $\mu$-oxo dimer; the concentrations of HA2 and iron(III) protoporphyrin IX were 4 and $400 \mu \mathrm{M}$, respectively.

This is indicative of the presence of the $\mu$-oxo-bridged species and not of the iron(III) monomer, which displays a $\beta$ band in the region of $630 \mathrm{~nm}$ (Silver \& Lukas, 1983; Miller et al., 1987). Importantly, this demonstrated that the $\mu$-oxo dimer was formed during the phase represented by the drop in $A_{365}$. Final confirmation of the production of $\mu$-oxo bishaem was provided by ATR FT-IR spectroscopy. To improve the IR spectroscopic detection of the $\mu$-oxo dimer, HA2 was incubated for $24 \mathrm{~h}$ with an increased concentration of iron(III) monomer $(400 \mu \mathrm{M})$ at a haem:protein molar ratio of 100:1 (Fig. 2). This revealed an absorbance band at $\sim 900 \mathrm{~cm}^{-1}$ attributable to the asymmetric stretching frequency of the oxo-bridged $\mathrm{Fe}-\mathrm{O}-\mathrm{Fe}$ dimer (Brown et al., 1969; Kapetanaki \& Varotsis, 2000). As a negative control, Fe(III)PPIX.OH was incubated with bovine albumin, which resulted in a Soret band with a $403 \mathrm{~nm} \lambda_{\max }$ (data not shown), indicating the formation of a haem monomeralbumin complex (Beaven et al., 1974; Kamal \& Behere, 2002 ) and not the $\mu$-oxo bishaem. The amounts of the $\mu$-oxo dimer formed and monomer depleted during incubation of HA2 with iron(III) protoporphyrin IX monomers were calculated from the $A_{365}$ and $A_{385}$ ratios and the millimolar extinction coefficients at these wavelengths (Fig. 3). As expected, we observed a low level of $\mu$-oxo dimer formation from some of the ferrihaem monomer in solution in the control (Inada \& Shibata, 1962). In contrast, incubation of $\mathrm{Fe}(\mathrm{III}) \mathrm{PPIX}$.OH with HA2 resulted in an immediate increase in the amount of $\mu$-oxo dimer and depletion of the monomer. Approximately $50 \%(10 \mu \mathrm{M})$ of the monomer was converted into $\mu$-oxo dimer after $1 \mathrm{~h}$. This is in reasonable agreement with the value of $14 \mu \mathrm{M}$ calculated using a
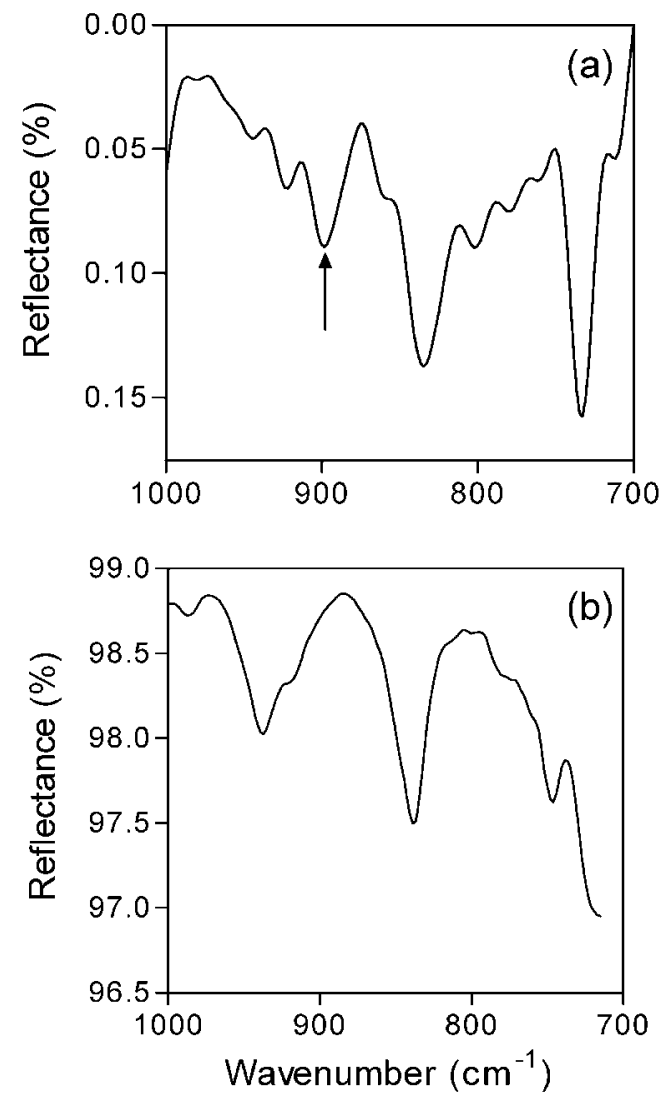

Fig. 2. ATR FT-IR spectra of (a) iron(III) protoporphyrin IX $(400 \mu \mathrm{M})$ after incubation with HA2 $(4 \mu \mathrm{M})$, showing the $900 \mathrm{~cm}^{-1}$ band attributable to the asymmetric stretching frequency of the oxo-bridged Fe-O-Fe dimer (arrowed); (b) control iron(III) protoporphyrin IX. Incubations were carried out for $24 \mathrm{~h}$ at $37^{\circ} \mathrm{C}$ in $250 \mathrm{mM}$ Tris $/ \mathrm{HCl}, \mathrm{pH} 7 \cdot 0$.

millimolar extinction coefficient of 5 (Silver \& Lukas, 1983) for the $608 \mathrm{~nm}$ band shown in Fig. 1. Incubation of iron(III) protoporphyrin IX monomers with purified Kgp also gave a series of spectra similar to those of HA2, characterized by a fall in $A_{365}$ and gradual shift in the Soret $\lambda_{\max }$ to $385 \mathrm{~nm}$ (Fig. 4). As for the HA2 protein, there was an initial rapid increase in the concentration of the $\mu$-oxo dimer formed in the presence of the Kgp polyprotein (Fig. 4, inset).

Taken together, these data show that the HA2 domain and the Kgp polyprotein can mediate dimerization of monomeric ferrihaems, accompanied by aggregation of the $\mu$-oxo bishaem. In this context, aggregation should not be confused with the process of bacterial aggregation, but rather be understood as the process of stacking of $\mu$-oxo dimers in solution through weak $\pi$-bonding interactions to give larger molecular aggregates (Brown et al., 1976, 1980).

A comparison was made between the polyprotein gingipains HRgpA and Kgp, and the single-chain protease RgpB, for the ability to promote dimerization and aggregation. As seen in Fig. 5, the spectra of the RgpB-haem and control 


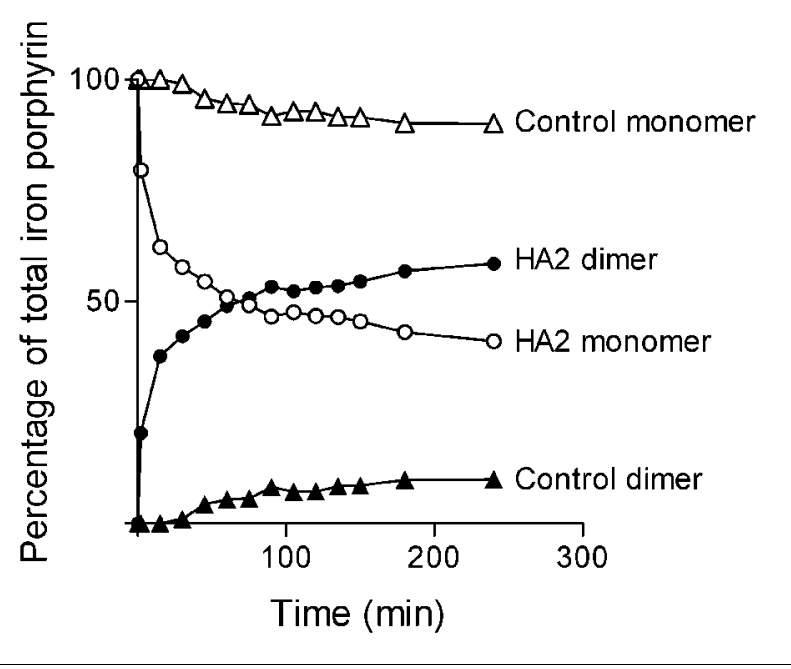

Fig. 3. Time-course of the formation of $\mu$-oxo dimer and depletion of monomer in the control and during incubation of HA2 with iron(III) protoporphyrin IX $(20 \mu \mathrm{M})$. The amounts of $\mu$-oxo dimer and monomer were calculated from the absorbances at 365 and $385 \mathrm{~nm}$, as derived from Fig. 1, and are expressed as a percentage of the total iron porphyrin concentration.

haem incubations were almost identical. In contrast, the HRgpA- and Kgp-haem incubations resulted in a broadening of the Soret band and greater reductions in intensity, indicative of a greater extent of $\mu$-oxo dimer formation and aggregation compared to the control or the RgpB protease. Reduction of Soret band absorbance intensity and broadening are measures of the extent of dimerization (Inada \& Shibata, 1962) and molecular aggregation of ferrihaems

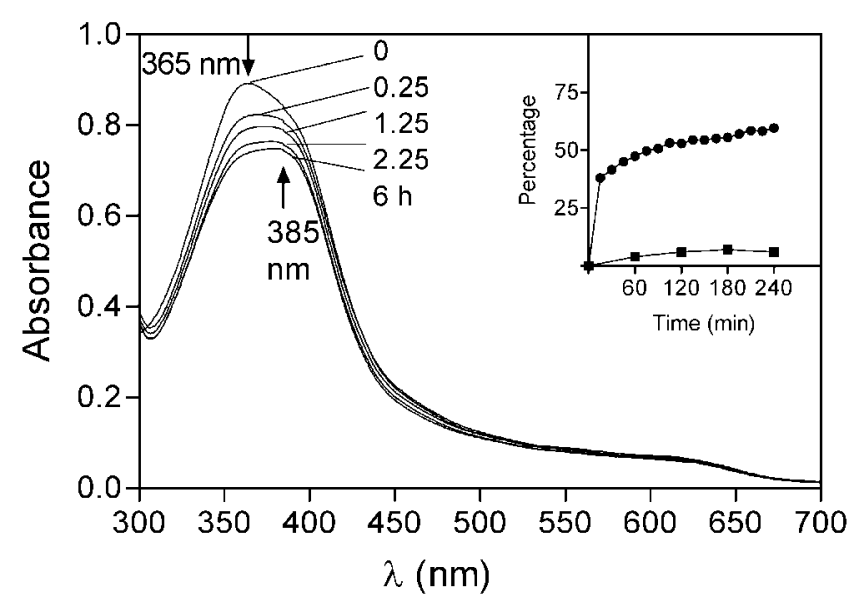

Fig. 4. UV-visible spectra of iron(III) protoporphyrin IX $(20 \mu \mathrm{M})$ incubated with purified $\mathrm{Kgp}(2 \mu \mathrm{M})$ at $37^{\circ} \mathrm{C}$ in $0.14 \mathrm{M} \mathrm{NaCl}$, $0.2 \mathrm{M}$ phosphate, $\mathrm{pH} 6 \cdot 5$. The inset shows the $\mu$-oxo dimer formed as a percentage of total iron porphyrin during incubation with $\mathrm{Kgp}(\boldsymbol{O})$ and in the control ( $\boldsymbol{\square})$.

(Wood et al., 2004), respectively. On this basis it was clearly demonstrated that both HRgpA and Kgp mediated greater dimer formation and aggregation than RgpB, which lacks the HA2 domain.

\section{DISCUSSION}

The covalent $\mu$-oxo bishaem complex, the major component of the haem pigment, forms through the spontaneous reaction between dioxygen and Fe(II)PPIX monomers

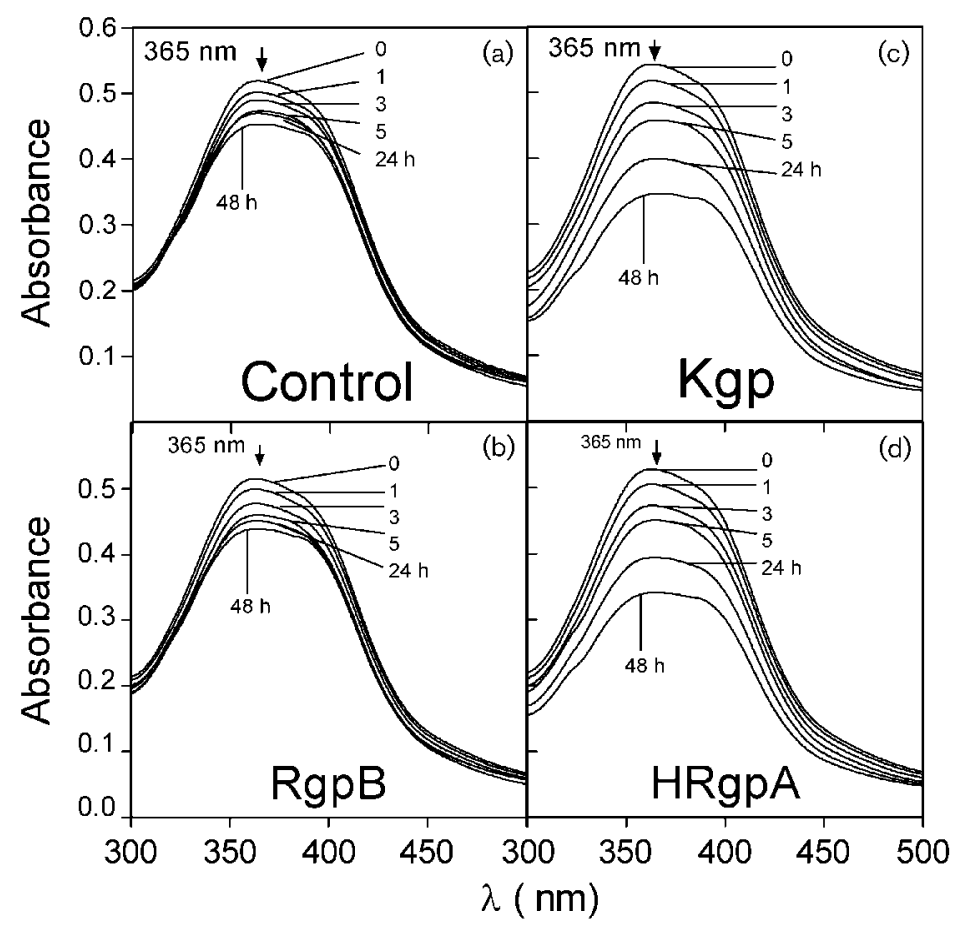

Fig. 5. UV-visible spectra of the Soret band regions of $10 \mu \mathrm{M}$ iron(III) protoporphyrin IX incubated with purified gingipains. (a) Control haem; (b) RgpB; (c) Kgp; (d) HRgpA. The iron porphyrin:protein ratio in each case was $100: 1$, and incubations were carried out at $37^{\circ} \mathrm{C}$ in $0.14 \mathrm{M} \mathrm{NaCl}, 0.2 \mathrm{M}$ phosphate, $\mathrm{pH} 6 \cdot 5$. 
proteolytically released by $P$. gingivalis from deoxyhaemoglobin [where the haems are in the iron(II) state] (Smalley et al., 2002):

(1) $4 \mathrm{Fe}(\mathrm{II}) \mathrm{PPIX}+\mathrm{O}_{2} \rightarrow 2[\mathrm{Fe}(\mathrm{III}) \mathrm{PPIX}]_{2} \mathrm{O}$

It also forms at a much slower rate through dimerization of iron(III) protoporphyrin IX monomers (Inada \& Shibata, 1962; Brown et al., 1970; Silver \& Lukas, 1983; Miller et al., 1987), according to the equation:

\section{(2) $2 \mathrm{Fe}(\mathrm{III})$ PPIX.OH $\rightarrow[\mathrm{Fe}(\mathrm{III}) \text { PPIX }]_{2} \mathrm{O}+\mathrm{H}_{2} \mathrm{O}$}

Because the $\mu$-oxo dimer is formed from Fe(III)PPIX.OH released from methaemoglobin (the oxidized form of haemoglobin) (Smalley et al., 2002), we examined interactions of $\mathrm{Fe}(\mathrm{III}) \mathrm{PPIX}$.OH with purified gingipains and the HA2 haemagglutinin, which is known to mediate haem binding to the Kgp and HRgpA polyproteins.

Using UV-visible spectroscopy, we demonstrated that the isolated HA2 protein can convert the monomeric iron(III) species into the $\mu$-oxo dimer. The formation of the covalent $\mathrm{Fe}-\mathrm{O}-\mathrm{Fe}$ bridged haem complex was confirmed using IR spectroscopy. The generation of the $\mu$-oxo dimer was accompanied by aggregation. In addition to the HA2 protein, $\mu$-oxo dimer formation was mediated by both Kgp and HRgpA polyproteins which possess this adhesin. The inability of RgpB to promote these effects is in keeping with its lack of HA2. Thus, in addition to acting as a multifunctional adhesin, the HA2 domain of Arg- and Lys-gingipains, which is identical in both gingipains (Pavloff et al., 1997), may play an important role in haem-pigment formation by facilitating both dimerization and aggregation of the $\mu$-oxo bishaem complex.

The mechanism of HA2-mediated dimer formation is not clear, but we speculate that this domain serves as a template to transiently bind $\mathrm{Fe}(\mathrm{III})$ monomers such that they may react with other $\mathrm{Fe}(\mathrm{III}) \mathrm{PPIX}$.OH molecules, either free in solution or bound to the protein, to form $\left[\mathrm{Fe}(\mathrm{III}) \mathrm{PPIX}_{2} \mathrm{O}\right.$ according to reaction (2). Newly formed $\mu$-oxo bishaem released from the protein would be free to aggregate through weak $\pi$-bonding interactions and porphyrin stacking to form micelles which would become segregated from solution (Brown et al., 1980). Rendering $\mu$-oxo dimer aggregates insoluble would result in greater monomer to dimer conversion so as to maintain the solution equilibrium between the monomeric and dimeric forms (Brown et al., 1976; Silver \& Lukas, 1983). This behaviour of the ferrihaems in aqueous solution would drive pigment production and may explain, in part, why $P$. gingivalis accumulates up to $50 \%$ of its biomass dry weight as haem (Rizza et al., 1968; Smalley et al., 1998 ) in the form of aggregated $\mu$-oxo dimer (Smalley et al., 1998, 2004).

$P$. gingivalis displays a $\mathrm{pH}$ growth optimum of $7 \cdot 5-8$ (McDermid et al., 1988), and its preferred habitats, the inflamed gingival sulcus and diseased periodontal pocket, have a slightly alkaline pH (Bickel \& Cimasoni, 1985; Eggert et al., 1991), which will promote $\mu$-oxo bishaem formation from Fe(III)PPIX.OH (Silver \& Lukas, 1983). Although acid $\mathrm{pH}$ ordinarily favours formation of $\mathrm{Fe}(\mathrm{III}) \mathrm{PPIX}$.OH monomers from the $[\mathrm{Fe}(\mathrm{III}) \mathrm{PPIX}]_{2} \mathrm{O}$ complex, Silver \& Lukas (1983) have shown that once formed at low $\mathrm{pH}, \mu$-oxo dimers remain stable. In this context, we demonstrated that $\mu$-oxo dimer formation was mediated by HA2, HRgpA and Kgp under slightly acid conditions ( $\mathrm{pH} 6 \cdot 5)$. This is significant, as it demonstrates that $P$. gingivalis may be capable of promoting $\mu$-oxo dimer pigment formation at below neutral $\mathrm{pH}$, such as in supragingival plaque, as well as in the subgingival environment.

Several other proteins are expressed by $P$. gingivalis which are involved in the binding and/or uptake of haem. These include outer-membrane proteins expressed under haem limitation (Bramanti \& Holt, 1993; Smalley et al., 1993), the iron haem transport protein (IhtB) (Hendtlass et al., 2000), the TonB-like proteins Tla and Tlr (Aduse-Opoku et al., 1997; Slakeski et al., 2000), the haem-regulated protein HemR (Karunakaran et al., 1997) and a haem/haemoglobinbinding receptor (HmuR) (Simpson et al., 2000, 2004). It should also be noted that the cell-surface haemagglutinin A (HagA) protein of $P$. gingivalis possesses four repeats of the HA2 domain sequence in its structure (Shi et al., 1999), but its role, and that of the above proteins in $\mu$-oxo bishaem formation, has not been investigated. Importantly, in addition to targeting the catalytic functions of the Arg- and Lysgingipains to abrogate the aggressive proteolytic nature and pathogenic potential of $P$. gingivalis, consideration must now be given to perturbing production of the protective haem pigment by inhibiting protease-mediated $\mu$-oxo bishaem formation from monomeric haem precursors.

\section{ACKNOWLEDGEMENTS}

The authors acknowledge the support of the National Institutes of Health grant DE 09761 and grant 3 PO4A 00324 from the Committee of Scientific Research (KBN, Poland) (to J. P.). J. P. is the recipient of an award 'subsydium profesorskie' from the Foundation for Polish Science (FNP, Warsaw, Poland). We would also like to thank Professor Stanley Brown for helpful comments and Dr Rui Chen, Department of Clinical Engineering, The University of Liverpool, UK, who performed the FT-IR.

\section{REFERENCES}

Aduse-Opoku, J., Slaney, J. M., Rangarajan, M., Muir, J., Young, K. A. \& Curtis, M. A. (1997). The Tla protein of Porphyromonas gingivalis W50: a homolog of the RI protease precursor (PrpRI) is an outer membrane receptor required for growth on low levels of hemin. J Bacteriol 179, 4778-4788.

Beaven, G. H., Chen, S.-H., D’Albis, A. \& Gratzer, W. B. (1974). A spectroscopic study of the hemin-human-serumalbumin system. Eur J Biochem 41, 539-546.

Bickel, M. \& Cimasoni, G. (1985). The pH of human crevicular fluid measured by a new microanalytical technique. J Periodont Res 20, 35-40.

Bramanti, T. E. \& Holt, S. C. (1993). Hemin uptake in Porphyromonas gingivalis: Omp26 is a hemin-binding protein surface protein. J Bacteriol 175, 7413-7420. 
Brown, S. B., Jones, P. \& Lantzke, I. R. (1969). Infrared evidence for an oxo-bridged (Fe-O-Fe) haemin dimer. Nature 223, 960-961.

Brown, S. B., Dean, T. C. \& Jones, P. (1970). Aggregation of ferrihaems: dimerization and protolytic equilibria of protoferrihaem and deuteroferrihaem in aqueous solution. Biochem J 117, 733-739.

Brown, S. B., Shillcock, M. \& Jones, P. (1976). Equilibrium and kinetic studies of the aggregation of porphyrins in aqueous solution. Biochem J 153, 279-285.

Brown, S. B., Hatzikonstantinou, H. \& Herries, D. G. (1980). The structure of porphyrins and haems in aqueous solution. Int J Biochem 12, 701-707.

Chen, Z., Potempa, J., Polanowski, A., Wikstrom, M. \& Travis, J. (1992). Purification and characterization of a $50-\mathrm{kDa}$ cysteine proteinase (gingipain) from Porphyromonas gingivalis. J Biol Chem 267, 18896-18901.

DeCarlo, A. A., Paramaesvaran, M., Yun, P. W., Collyer, C. \& Hunter, N. (1999). Porphyrin-mediated binding to hemoglobin by the HA2 domain of cysteine proteinases (gingipains) and hemagglutinins from the periodontal pathogen Porphyromonas gingivalis. J Bacteriol 181, 3784-3791.

Eggert, F. M., Drewell, L., Bigelow, J. A., Speck, J. E. \& Goldner, M. (1991). The $\mathrm{pH}$ of gingival crevices and periodontal pockets in children, teenagers and adults. Arch Oral Biol 36, 233-238.

Hendtlass, A., Dashper, S. G. \& Reynolds, E. C. (2000). Identification of an antigenic protein Pga30 from Porphyromonas gingivalis W50. Oral Microbiol Immunol 15, 383-387.

Holt, S. C., Ebersole, J., Felton, J., Brunsvold, M. \& Kornman, K. S. (1988). Implantation of Bacteroides gingivalis in nonhuman primates initiates progression of periodontitis. Science 239, 55-57.

Inada, Y. \& Shibata, K. (1962). The Soret band of monomeric hematin and its changes on polymerization. Biochem Biophys Res Commun 9, 323-327.

Kamal, J. K. A. \& Behere, D. V. (2002). Spectroscopic studies on human serum albumin and methemalbumin: optical, steady-state, and picosecond time-resolved fluorescence studies, and kinetics of substrate oxidation by methemalbumin. J Biol Inorg Chem 7, 273-283.

Kapetanaki, S. \& Varotsis, C. (2000). Ferryl-oxo heme intermediate in the antimalarial mode of action of artemesinin. FEBS Lett 474, 238-241.

Karunakaran, T., Madden, T. \& Kuramitsu, H. (1997). Isolation and characterization of a hemin-regulated gene, hemR, from Porphyromonas gingivalis. J Bacteriol 179, 1898-1908.

Machtei, E. E., Dunford, R., Hausmann, E., Grossi, S. G., Powell, J., Cummins, D., Zambon, J. J. \& Genco, R. J. (1997). Longitudinal study of prognostic factors in established periodontitis patients. J Clin Periodontol 24, 102-109.

McDermid, A. S., McKee, A. S. \& Marsh, P. D. (1988). Effect of environmental $\mathrm{pH}$ on enzyme activity and growth of Bacteroides gingivalis W50. Infect Immun 56, 1096-1100.

Miller, J. R., Taies, J. A. \& Silver, J. (1987). Mössbauer and spectroscopic studies on substituted tetraphenylporphyrinato iron(III) complexes in aqueous solutions and formation of the $\mu$-oxo-bridged species. Inorg Chim Acta 138, 205-214.

Nakayama, K., Ratnayake, D. B., Tsukub, T., Kadowaki, T., Yamamoto, K. \& Fujimura, S. (1998). Haemoglobin receptor is intragenically encoded by the cysteine proteinase-encoding genes and the haemagglutinin-encoding gene of Porphyromonas gingivalis. Mol Microbiol 27, 51-61.

Olczak, T., Dixon, D. W. \& Genco, C. A. (2001). Binding specificity of the Porphyromonas gingivalis heme and hemoglobin receptor HmuR, gingipain $\mathrm{K}$, and gingipain $\mathrm{R} 1$ for heme, porphyrins, and metalloporphyrins. J Bacteriol 183, 5599-5608.
Paramaesvaran, M., Nguyen, K. A., Caldon, E. \& 8 other authors (2003). Porphyrin-mediated cell surface heme capture from hemoglobin by Porphyromonas gingivalis. J Bacteriol 185, 2528-2537. Pavloff, N., Pemberton, P. A., Potempa, J., Chen, W. C., Pike, R. N., Prochazka, V., Kiefer, M. C., Travis, J. \& Barr, P. J. (1997). Molecular cloning and characterization of Porphyromonas gingivalis lysinespecific gingipain. A new member of an emerging family of pathogenic bacterial cysteine proteinases. J Biol Chem 272, 1595-1600.

Pike, R., McGraw, W., Potempa, J. \& Travis, J. (1994). Lysine- and arginine-specific proteinases from Porphyromonas gingivalis. Isolation, characterization, and evidence for the existence of complexes with hemagglutinins. J Biol Chem 269, 406-411.

Potempa, J., Pavloff, N. \& Travis, J. (1995). Porphyromonas gingivalis: a proteinase/gene accounting audit. Trends Microbiol 3, 430-434.

Potempa, J., Mikolajczyk-Pawlinska, J., Brassell, D., Nelson, D., Thogersen, I. B., Enghild, J. J. \& Travis, J. (1998). Comparative properties of two cysteine proteinases (gingipain Rs), the products of two related but individual genes of Porphyromonas gingivalis. J Biol Chem 273, 21648-21657.

Potempa, J., Pike, R. \& Travis, J. (1997). Titration and mapping of the active site of cysteine proteinases from Porphyromonas gingivalis (gingipains) using peptidyl chloromethanes. Biol Chem 378, 223-230.

Potempa, J., Banbula, A. \& Travis, J. (2000). Role of bacterial proteinases in matrix destruction and modulation of host responses. Periodontology 2000 24, 153-192.

Rizza, V., Sinclair, P. R., White, D. C. \& Cuorant, P. R. (1968). Electron transport system of the protoheme-requiring anaerobe Bacteroides melaninogenicus. J Bacteriol 96, 665-671.

Shi, Y., Ratnayake, D. B., Okamoto, K., Abe, N., Yamamoto, K. \& Nakayama, K. (1999). Genetic analyses of proteolysis, hemoglobin binding, and hemagglutination of Porphyromonas gingivalis. Construction of mutants with a combination of $\operatorname{rgp} A, \operatorname{rgp} B, k g p$, and hagA. J Biol Chem 274, 17955-17960.

Silver, J. \& Lukas, B. (1983). Mössbauer studies on protoporphyrin IX iron(III) solutions. Inorg Chim Acta 80, 107-113.

Simpson, W., Olczak, T. \& Genco, C. A. (2000). Characterization and expression of HmuR, a TonB-dependent hemoglobin receptor of Porphyromonas gingivalis. J Bacteriol 182, 5737-5748.

Simpson, W., Olczak, T. \& Genco, C. A. (2004). Lysine-specific gingipain $\mathrm{K}$ and heme/hemoglobin receptor HmuR are involved in heme utilization in Porphyromonas gingivalis. Acta Biochim Pol 51, 253-262.

Slakeski, N., Dashper, S. G., Cook, P., Poon, C., Moore, C. \& Reynolds, E. C. (2000). A Porphyromonas gingivalis genetic locus encoding a heme transport system. Oral Microbiol Immunol 15, 388-392.

Smalley, J. W., Birss, A. J., McKee, A. S. \& Marsh, P. D. (1993). Haem-binding proteins of Porphyromonas gingivalis W50 grown in a chemostat under haemin-limitation. J Gen Microbiol 139, 2145-2150.

Smalley, J. W., Silver, J., Marsh, P. J. \& Birss, A. J. (1998). The periodontopathogen Porphyromonas gingivalis binds iron protoporphyrin IX in the $\mu$-oxo dimeric form: an oxidative buffer and possible pathogenic mechanism. Biochem J 331, 681-685.

Smalley, J. W., Birss, A. J. \& Silver, J. (2000). The periodontal pathogen Porphyromonas gingivalis harnesses the chemistry of the $\mu$-oxo bishaem of iron protoporphyrin IX to protect against hydrogen peroxide. FEMS Microbiol Lett 183, 159-164.

Smalley, J. W., Birss, A. J., Withnall, R. \& Silver, J. (2002). Interactions of Porphyromonas gingivalis with oxyhaemoglobin and deoxyhaemoglobin. Biochem J 362, 239-245.

Smalley, J. W., Charalabous, P., Hart, C. A. \& Silver, J. (2003). Transmissible Burkholderia cepacia genomovar IIIa strains bind and convert monomeric iron(III) protoporphyrin IX into the $\mu$-oxo oligomeric form. Microbiology 149, 843-853. 
Smalley, J. W., Thomas, M. F., Birss, A. J., Withnall, R. \& Silver, J. (2004). A combination of both arginine- and lysine-specific gingipain activity of Porphyromonas gingivalis is necessary for the generation of the $\mu$-oxo bishaem-containing pigment from haemoglobin. Biochem J 379, 833-840.

Sroka, A., Sztukowska, M., Potempa, J., Travis, J. \& Genco, C. A. (2001). Degradation of host heme proteins by lysine- and argininespecific cysteine proteinases (gingipains) of Porphyromonas gingivalis. J Bacteriol 83, 5609-5616.
Sztukowska, M., Sroka, A., Bugno, M., Banbula, A., Takahashi, Y., Pike, R. N., Genco, C. A., Travis, J. \& Potempa, J. (2004). The $\mathrm{C}$-terminal domains of the gingipain $\mathrm{K}$ polyprotein are necessary for assembly of the active enzyme and expression of associated activities. Mol Microbiol 54, 1393-1408.

Wood, B. R., Langford, S. J., Cooke, B. M., Lim, J., Glenister, F. K., Duriska, M., Unthank, J. K. \& McNaughton, D. (2004). Resonance Raman spectroscopy reveals new insight into the electronic structure of $\beta$-hematin and malaria pigment. J Am Chem Soc 126, 9233-9239. 